\title{
Intercultural Human Resource Management: South Korea And The United States
}

Robin Self, Ph.D., Alabama State University, USA

Donald R. Self, D.B.A., Auburn University Montgomery, USA

Janel Bell-Haynes, Alabama State University, USA

\begin{abstract}
The southern region of the United States has been recruiting South Korean firms to locate their manufacturing operations there. Alabama and Georgia have been successful in recruiting Hyundai and Kia to build automotive manufacturing plants, and in attracting first and second-tier suppliers as well, providing an estimated 4,000 jobs to the area. The mix of foreign and domestic employees and diverse human resource practices presents both opportunities and challenges. As indicated by Hofstede (1991), management practices and values differ from country to country due to each nation's unique culture and traditions. Hofstede $(1991,2001)$ provides a framework for examining the cultural differences between South Korea and the United States. Additionally, Hargittay and Kleiner (2005) posit that the cultural norms in Korea have been heavily influenced by Confucianism, while in the United States people have been influenced by the Protestant work ethic. These cultural differences impact the following organizational behavior and human resource management issues: leadership styles, organizational structure, organizational communication, recruitment and hiring practices, job security, and performance appraisal.
\end{abstract}

Keywords: international business; South Korea; cross-cultural; organizational behavior; human resource practices

\section{INTRODUCTION}

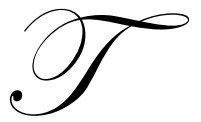

he southern region of the United States has been actively recruiting South Korean firms to locate their manufacturing operations there. In 2002, Hyundai Motor Company (HMC), Korea's largest automotive manufacturer, announced plans that it would construct a $\$ 1$ billion automotive assembly and manufacturing plant in Montgomery, Alabama. This plant is the company's first manufacturing base in the United States, and employs more than 2,700 people. Also, more than 72 suppliers have located businesses throughout North America to support Hyundai's plant. In 2006, the facility started production, and produces 300,000 vehicles a year at full capacity (www.hmmausa.com, 2009).

Kia Motors, a South Korean automaker with 12 straight years of U.S. sales gains, selected a manufacturing site in West Point, Georgia, but it created more automotive jobs for Alabama as well. The Kia facility, its first in the U.S., is scheduled to begin production in 2010 and produce 300,000 vehicles a year and employ 2,500 people. As many as six suppliers will set up operations in the surrounding area resulting in an additional 6,000 jobs. Hyundai Mobis, a major automotive supplier for Kia Motors Corp., also located a facility in Georgia, creating 600 jobs. The Kia plant is the largest project in the history of the State of Georgia and is already having a positive impact on the economy; more than 43,000 individuals applied for 2,500 jobs in the Kia plant (kmmgusa.com, 2009).

This mix of foreign and domestic employees and diverse human resource practices presents both opportunities and challenges. As indicated by Hofstede (1991), management practices and values differ from country to country due to each nation's unique culture and traditions. Therefore, Hofstede's (1991, 2001) framework is used as a basis for examining the cultural differences between South Korea and the United States on the following dimensions: power distance, individualism/collectivism, uncertainty avoidance, achievement and nurturing, and long-term vs. short term orientation. Additionally, Hargittay and Kleiner (2005) posit that the 
cultural norms in Korea have been heavily influenced by Confucianism, while in the United States, people have been influenced by the Protestant work ethic.

After exploring the national cultural differences between the two countries, this paper analyzes and compares aspects of organizational behavior and human resource management in South Korea with those same practices in the United States. Specifically, leadership styles, organizational structure, organizational communication, recruitment and hiring practices, job security, and performance appraisal will be examined.

\section{NATIONAL CULTURAL DIMENSIONS}

The cultural heritage of most nations has a great impact on its societal, economic and political structure. These, in turn, influence the development of management practices and values found in the country; these management practices differ from country to country due to each nation's unique culture and traditions. Geert Hofstede's $(2003,2001,1991)$ framework for assessing cultures is one of the most widely cited approaches for helping managers understand differences between national cultures. In his research he found that managers and employees vary on five dimensions of national culture: (1) individualism vs. collectivism, (2) power distance, (3) uncertainty avoidance, (4) achievement versus nurturing, and (5) long-term and short-term orientation. Each dimension is described below, followed by a comparison of the scores of South Korea and the United States.

Individualism vs. Collectivism concerns the extent to which people in a country prefer to act as individuals or as members of groups. According to Hofstede, (2003) "on the individualist side we find societies in which ties between individuals are loose: everyone is expected to look after him/herself and his/her immediate family. On the collectivist side, we find societies in which people from birth onwards are integrated into strong cohesive in-groups, often extended families which continue protecting them in exchange for unquestioning loyalty" (p. 2-3).

South Korea has a low Individualism (IDV) score of 18, indicating that the society is collectivist rather than individualist. Hofstede contends that this is manifested in a close long-term commitment to the member group, such as a family, extended family, or extended relationships. Loyalty in a collectivist culture is of utmost importance and overrides most other societal rules and regulations. This culture promotes strong relationships where everyone takes responsibility for fellow members of their group. Conversely, the United States is one of only 7 countries in the Hofstede research that has Individualism as their highest dimension: 91. "The high Individualism ranking indicates a society with a more individualist attitude and relatively loose bonds with others" (Hofstede, 2003, p. 2 -3).

The second dimension, Power Distance, is a measure of the extent to which society accepts the fact that power in organizations is distributed unequally. High power distance societies tend to accept inequalities while low power distance societies play down inequities. South Korea has a Power Distance score of 60 while the United States has a score of 40 (world average $=55$ ). "This indicates that the United States has greater equality between societal levels, including government, organizations, and even within families. This orientation reinforces a cooperative interaction across power levels and creates a more stable cultural environment" (Hofstede, 2003, p. 2).

Uncertainty Avoidance, the third dimension, is the degree to which people tolerate risk and prefer structured over unstructured situations. Low uncertainty avoidance societies are comfortable with risks while high uncertainty avoidance societies feel threatened by uncertainty and ambiguity. The United States had a score of 46, Korea had a score of 85 and the world average was 64 . The United States' low ranking indicates "a society that has fewer rules and does not attempt to control all outcomes and results. It also has a greater level of tolerance for a variety of ideas, thoughts, and beliefs" (Hofstede, 2003, p. 3). Of the five dimensions, South Korea's highest score is in Uncertainty Avoidance indicating the society's low level of tolerance for uncertainty. In an effort to minimize or reduce this level of uncertainty, strict rules, laws, policies, and regulations are adopted and implemented. The ultimate goal of this population is to control everything in order to eliminate or avoid the unexpected. As a result of this high Uncertainty Avoidance characteristic, the society does not readily accept change and is very risk adverse.

The fourth dimension, Masculinity vs. Femininity, refers to the distribution of roles between the two genders. Women's values differ less among societies than men's values. Men's values contain a dimension ranging 
from very assertive and competitive to modest and caring. The assertive pole is termed masculine while the modest pole is termed feminine. The United States had a ranking of 62, compared to Korea's ranking of 39 and a world average of 50. According to Hofstede (2003), the United States "experiences a higher degree of gender differentiation of roles. The male dominates a significant portion of the society and power structure. This situation generates a female population that becomes more assertive and competitive, with women shifting toward the male role model and away from their female role" (p. 3). The women in feminine countries have the same modest, caring values as the men, but in the masculine countries they are somewhat assertive and competitive, but not as much as the men. Therefore, these countries show a gap between men's values and women's values (Hofstede, 2003).

Long term and short term orientation, the fifth dimension, refers to a country's orientation toward life and work. Countries with a long-term orientation look to the future and value thrift and persistence. Countries with a short term orientation, such as the United States, have respect for tradition, fulfilling social obligations, and protecting one's face. The short term orientation for the United States is the lowest dimension for the U.S. (29) compared to the world average of 45, and a South Korean score of 70. The long term orientation of South Koreans indicates values of thrift and perseverance (Hofstede, 2003, p. 3). Figure 1 presents Hofstede's 5 Dimensional Model comparing the scores of South Korea and the United States.

To summarize, South Korea is characterized by large power distance and authoritarianism, collectivism and communitarianism (associated with family and clan membership), and strong uncertainty avoidance. The United States is characterized by a focus on the individual, short-term orientation, low power distance, tolerance for risk and ambiguity, and a masculine society.

In addition to Hofstede's findings, Hargittay and Kleiner (2005) contend that the cultural norms in Korea have been heavily influenced by Confucianism, while the Protestant work ethic has influenced people in the United States. In general, Confucianism stresses harmony among people and encourages an environment in business that depends on groups and teamwork. The Protestant work ethic is based on the ability of the individual, leading to the individualist type of environment found in the United States today. These national cultural differences have implications for organizational behavior issues and human resource practices in organizations.

Figure 1: Hofstede's 5D Model of South Korea and the United States

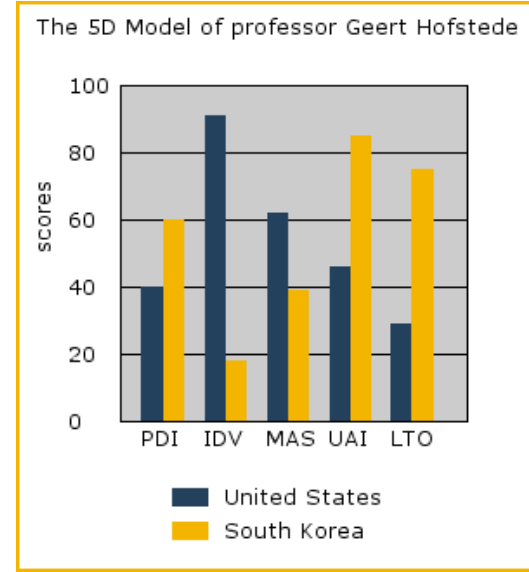

Source: ITIM international, Geert Hofstede Cultural Dimensions (www.geerthofstede.com/hofstede_dimensions.php?culture $1=95 \%$ culture $2=82$ )

\section{ORGANIZATIONAL BEHAVIOR AND HUMAN RESOURCE MANAGEMENT IMPLICATIONS}

Organizational behavior and human resource management concerns individual behavior, group behavior and organizational aspects such as structure, culture and human resources policies and practices. Specific issues impacted by cultural differences include leadership styles, organizational structure, organizational communication, recruitment and hiring practices, job security, and performance appraisal. 


\section{Leadership}

The importance of leadership in an organization cannot be overemphasized. According to Mills (2005), business leadership is the core of economic development. Managers and entrepreneurs who sustain and create companies is at the core of both Korean and American economic development. The contrast between South Korea and the United States on the individualism-collectivism dimension and the power distance dimension directly impacts leadership styles in organizations.

Mills (2005) contends that American CEOs tend to use one of the following leadership styles: directive, participative, empowering, or charismatic.

While the directive leadership style is well known in America, its use is declining in frequency in the U.S. It stresses the direction given by executives to others in the firms and the leader is very much in charge. Of the five styles, this style is most common in South Korea (Mills, 2005).

Participative leadership, which involves close teamwork with others, is more common in America than South Korea. Empowering leadership is relatively new and stresses delegation of responsibility to subordinates. American companies that operate with largely autonomous divisions employ this style of leadership. A few younger Asian business leaders now use this style (Mills, 2005).

A charismatic leader is the one who looks like a leader. People follow this person because of who he/she is, not because of good management or even business success. Human magnetism is the attraction, and it is very different in different national cultures. What looks like a charismatic leader to Americans may appear to be something very different to people from other cultures.

Fukuyama (1995) contends that "virtually all comparative studies of Korean management have indicated that Korean businesses tend to be run in a hierarchical, authoritarian, and centralized manner" (p. 134). The authoritarian nature of decision making in Korea makes it easier for Korean companies to move quickly and decisively (Morden \& Bowles, 1998). Welch, Kily and Ihlwan (2008) found that the top executives in the United States' Hyundai plants run the companies in a far more authoritarian style than do most American CEOS.

The stage of development of a company also influences the type of leadership in the firm. To a significant degree, large American firms are at a later stage of development than many Asian firms - they have passed from founders' family leadership to professional management (many companies have executive development programs within the firm). According to Mills (2005), American CEOs average about 30 years with their firms and own less than 4 percent of its shares. Additionally, many American firms are more dependent on capital markets for their capital (equity and debt) and so pay more attention to Wall Street than is yet common in Asia. There is less freedom of action for executives and boards in America than in Asia. In this transition they have adopted particular styles of leadership responsive to boards (often lead by outside directors) and to the U.S. stock market (Mills, 2005).

To summarize, American businesses tend to use a variety of leadership styles, while South Korean business leaders tend to follow a directive leadership style. American firms tend to be in a later stage of development, with professional managers leading the companies. One additional factor that influences leadership styles in the two countries is family/political connections.

Two levels of organization exist in South Korea: individual firms, and larger networks which unite these individual corporate entities. The Korean conglomerate networks or business groupings are known as the chaebol. Virtually the whole of the large business sector in South Korea is part of one or other of the chaebol networks which are usually family-owned or controlled and kinship based. Examples include corporations such as Samsung, Hanjiin, Daewoo, Hyundai, and Lucky-Goldstar (LG) (Morden \& Bowles, 1998, p. 318).

Chaebols are extremely large and sophisticated and have maintained close relationships with the Korean government. The chaebols have expanded very rapidly in the world market and produce major international brands. Many of the chaebols are still run by founding family members, who insist on making all major management decisions personally. Therefore, ownership and management have not been separated in many large South Korean companies. The owner family has actively participated in the management process and family members tend to 
dominate the positions of power. This is due in part to being members of an extended clan, the chiban, which provides broad-based security for family and clan members (Morden \& Bowles, 1998; Chen, 1995).

The lynchpin that has held the different activities of the chaebol together and given them direction, has been consistent and assertive leadership by the autocrat or taipan. The taipan gives a point of focus and power such that activities are coordinated and decisions are made (Morden \& Bowles, 1998). According to Cragg (1995), "the taipans of Korea and their business culture are said to be the world's toughest. These businessmen are fearless in their ability to use pae-gi, that is, aggressive determination, to overcome obstacles from any quarter" (p. 137). To summarize, the chaebol, chiban, and taipans tend to reinforce the authoritarian nature of decision making in South Korea and make it easier for companies to move quickly and decisively. This more directive style may also mean that decisions are not adequately considered by staff and may be made with insufficient knowledge (Morden \& Bowles, 1998).

The political connections important for top business leaders in Korea are not unknown but are much less important in America. It is a characteristic of Asian top executives that they have such connections that are important to their businesses. In America, the CEOS of very large firms often have virtually no direct connections to top politicians (Mills, 2005).

To summarize, leaders and decision makers in Korea manage their corporations based on the principles of the family or clan system. This paternalistic and authoritarian approach leads to a top-down decision-making process (Hargittay \& Kleiner, 2005). American firms have a more participative leadership and decision making style with input from the bottom up.

\section{Organizational Structure}

Organizational structure is also impacted by national culture, particularly power distance and uncertainty avoidance. Organizational structure issues include departmentalization, specialization, centralization and decentralization, and formalization.

Departmentalization is concerned with how jobs are grouped together. According to Chen (1995), Korean companies place great importance on functional specialization such as planning, finance, and human resource management. "Many Korean companies have a combined organizational structure placing a vertical concentration of decision-making power at the senior levels of management and a horizontal concentration of functional control in staff departments" (Morden \& Bowles, 1998, p. 321). With authority concentrated at senior levels of management, there tends to be a tall hierarchical structure with many levels of hierarchy. American companies tend to use one of the following organizational structures: simple, functional, divisional, team, matrix, or project. The type of structure chosen is dependent on the strategy of the company, the size of the company, technology used and the degree of environmental uncertainty.

Both the power distance dimension and the uncertainty avoidance dimension impact centralization and formalization in South Korean companies. South Korea's high power distance score is reflected in the centralized structure of many South Korean companies. According to Chen (1995), "usually 80 percent of the authority lies in the upper management level, with middle or lower management having very limited authority." Hargittay and Kleiner (2005) found that the structure of Korean firms has affected the attitude of subordinates; "as one goes farther down the hierarchy of a Korean firm the more passive the employees are, leading to very few suggestions coming from the bottom" (p. 60). In an effort to minimize uncertainty, South Korean companies tend to have a high degree of formalization in their organizational structure relying on rules, policies, and regulations to reduce uncertainty.

\section{Organizational Communication}

Power distance differences between South Korea and the United States influence communication in organizations. In South Korean companies, formal communication is mainly along vertical hierarchies reflecting their high score on power distance. Superiors give directives while subordinate carry them out. Morden and Bowles 
(1998) contend that superiors tend to issue general directives, as opposed to specific and detailed ones. Subordinates then must use their own judgment about how to implement the directives. Chen (1995) maintains that this preference for communicating in general terms, combined with a relatively high power distance, comprises a major source of misunderstanding in Korean companies. South Koreans are reticent about open communication in formal meetings and have difficulty in airing their views, especially opposing ones (Chen, 1995). Morten (1996) found that South Korean companies tend to obtain information from, and place more reliance on, personal and family networks, rather than a formal research base or information sources that are available to them, which reflects their high score on collectivism.

Hargittay and Kleiner (2005) maintain that Korean employees usually attach much greater importance to upward formal communication on hierarchical lines rather than to communication on horizontal departmental lines.

Like South Korean companies, American companies use a combination of both formal and informal communication. However, the type of communication network used in the organization (chain, wheel, and allchannel) depends on the strategy and structure of the organization. For example, the wheel network is used when there is a strong leader, while the all-channel network is used when communication flows freely among all members of a work team without a designated leader. American workers report more satisfaction with all channel networks and low member satisfaction with the wheel. However, the wheel has the advantage of being fast with high accuracy (Robbins \& Coulter, 2007).

National culture also impacts the following human resource management practices in organizations: and recruitment and hiring, job security, performance appraisal.

\section{Recruitment and hiring}

Morden and Bowles (1998) contend that "professional managers and executives are becoming an increasingly powerful force in South Korean companies" (p. 319). Chen (1995) notes that "many of these managers are recruited through open competition from elite social groups." Common geographical and school/university ties play an important role in the formation of management power groups. Chen (1995) adds that a common practice is for owners to bring their school (or university) and hometown friends into management. In some Korean companies, top management positions are predominately filled by those who are from the same geographical area while in other companies, graduates from elite universities, like Seoul National, dominate top management.

This practice is in stark contrast to laws and regulations in the United States concerning recruitment and hiring practices. In the United States, the federal government has enacted a number of laws and regulations that influence the recruitment and hiring process. For example, decisions regarding who will be hired, or which employees will be chosen for a training program must be made without regard to race, sex, religion, age, color, national original or disability. Affirmative action, where an organization actively seeks to enhance the status of members from protected groups, may also be an issue. Therefore, U.S. managers are not completely free to choose whom they hire, promote, or fire. Although laws and regulations have helped reduce employment discrimination and unfair unemployment practices, they have at the same time, reduced managers' discretion over human resource decisions (Robbins \& Coulter, 2007).

\section{Job Security}

In South Korea there is traditional respect for authority, seniority, and job status. A significant degree of loyalty to the employer or taipan has been expected. The South Koreans display humanist characteristics in that employees are regarded as an important asset. Training is seen as an integral part of the business activity and companies above a certain size are required by law to provide training for their staff (Morden \& Bowles, 1998).

Chen (1995) comments that "Koreans are highly motivated workers and known for enduring long work days. The motivation of Korean workers is influenced by traditional values as well as by realistic needs. The key Confucian values of diligence and harmony have contributed to a relatively high work ethic. While the specific motivations of Korean employees vary dependent on the size of the company and the level of seniority, high wages 
and job security tend to be the most important motivational factors (Morden \& Bowles, 1998).

Conversely, in the United States, employees are not guaranteed job security and tenure in an organization is typically based on job performance (performance evaluation measures) rather than guaranteed job security.

\section{Performance Appraisal}

In the past, Korean managers rewarded and promoted employees based on seniority. However, today they are beginning to consider performance as well. Korean companies have gradually combined seniority with performance in determining rewards. While wages are generally based on seniority, bonuses may be rewarded based on performance (Chen, 1995).

Management practices and values in the United States are much more Darwinian in nature, according to Hargittay and Kleiner (2005). Americans tend to believe in the idea that the strong will survive and the weak will perish on an individual basis. This leads to interdepartmental competition which can have a negative impact on the organization. In general, rewards and promotions are based on the individual's success or failure, rather than group.

\section{CONCLUSION AND IMPLICATIONS FOR FUTURE RESEARCH}

Hofstede's cultural dimensions have been shown to influence organizations in both South Korea and the United States. South Korea's high scores on collectivism and power distance, juxtaposed with the United State's scores on individualism and power distance result in different practices, often conflicting, in organizations. When companies move their operations from their home country, both home and host countries must be sensitive to how these national cultural issues impact organizational behavior and human resource practices.

Future research in this area could benefit from an empirical examination of how best companies can merge the different cultures, and what impact this has on organizational performance.

\section{AUTHOR INFORMATION}

Dr. Robin Self, Professor of Management, has been a member of the Alabama State University faculty since 1991. She has degrees from the University of Georgia (BA - Communications 1978, MA - Communications 1981) and Georgia State University (Ph.D. - Management, 1991). Prior to joining Alabama State University, she taught at the University of Georgia and Georgia Southern University. Dr. Self has over 30 articles and conference papers in the areas of organization commitment and socialization, health care marketing, strategy, and culture including publications in the Journal of Applied Psychology, Journal of Management, Journal of Managerial Issues, and Health Marketing Quarterly. She has received several awards for teaching and research.

Donald R. (Don) Self is Distinguished Teaching Professor and Lowder/Weil Chair at Auburn University Montgomery (USA). He received the DBA degree from Louisiana Tech University in 1977 and has been a university teacher since 1970. He has received various teaching and research awards including the SherwinWilliams Distinguished teaching award from the Society of Marketing Advances. Don served ten years as the founding editor of the Journal of Non-profit and Public Sector Marketing and served as Associate Editor of the Journal of Marketing and the Journal of Professional Selling and Sales Management. He has edited or co-edited seven books.

Janel Bell Haynes is an eighteen year communications, and marketing veteran with unique skills in project management, sales, and fundraising. A collegiate adjunct instructor for more than ten years she has held positions in the education, government, corporate and private sectors. Her specific and most recent experience includes strategic communications and media planning for a comprehensive regional university. Her professional career began as a hospitality and tourism professional in sales and marketing; currently she is a full-time instructor of marketing and acting chair for the Business Administration Department in the College of Business at Alabama State University. 


\section{REFERENCES}

1. Background Note: South Korea. (2008). U. S. Department of State, www.state.gov/r/pa/ei/bgnl/2800.htm

2. $\quad$ Chen, M. (1995). Asian Management Systems. Routledge, London.

3. $\quad$ Cragg, C. (1995). The New Taipans. Century Business, London.

4. Fukuyama, F. (1995). Trust: the Social virtues and the creatiaon of prosperity. Hamish Hamilton, London.

5. Hargittay, P., \& Kleiner, B. (2005). Effectively Managing Korean-American Businesses, Management Research News, 28, 6, 55-65.

6. Hofstede, G. (1991). Cultures and Organizations. McGraw-Hill, London.

7. Hofstede, G. (2001). Culture's consequences. Thousand Oaks, CA: Sage Publications.

8. Hofstede, G. (2003). ITIM international, Geert Hofstede Cultural Dimensions www.geerthofstede.com/hofstede dimensions.php?culture $1=95 \%$ culture $2=82$.

9. Mills, D. Q. (2005, June 27). Asian and American Leadership Styles: How are they Unique. Harvard Business School Working Knowledge. (http://hbswk.hbs.edu/item/4869.html)

10. Morden, A. R. (1996). Principles of Management, McGraw-Hill, London.

11. Morden, T., \& Bowles, D. (1998). Management in South Korea: A review. Management Decisions, 36/5. MCB University Press. 316-330.

12. Robbins, S., \& Coulter, M. (2007). Management ( $9^{\text {th }}$ edition).Pearson: Upper Saddle River, NJ.

13. Welch, D., Kiley, D., \& Ihlwan, M. (2008, March). My Way or the Highway at Hyundai: The Korean carmaker and its Kia subsidiary are trying to move upscale in the U.S.--but culture clashes, management turmoil, and strategic discord are making for a bumpy ride. Business Week,(4075), 48-51. Retrieved September 25, 2008, from ABI/INFORM Complete database. (Document ID: 1444912461). 